\title{
The fate of water in the rumen
}

\section{2.* Water balances throughout the feeding cycle in sheep}

\author{
BY A. C. I. WARNER AND B. D. STACY \\ CSIRO, Division of Animal Physiology, The Ian Clunies Ross \\ Animal Research Laboratory, Prospect, NSW, Australia
}

(Received 30 August 1967-Accepted 12, February 1968) I. The ${ }^{51} \mathrm{Cr}$ complex of ethylenediamine tetra-acetic acid was used as a soluble marker
substance in sheep fed restricted amounts ( $700 \mathrm{~g}$ daily) of roughage diets. It was injected into
the rumen at various stages of the feeding cycle and rumen volumes and flow rates were calculated.

2. The average resting rumen volume for sixteen sheep (average body-weight $39 \mathrm{~kg}$ ) was $3.9 \mathrm{l}$; the average resting dilution rate was $0.07 \mathrm{~h}^{-1}$ so that the net inflow rate averaged $0.29 \mathrm{l} . /$ $h$; the average rate of absorption of water from the resting rumen into the blood was $0.051 . / h$.

3. There were marked differences in all these values, both within sheep on different days (coefficient of variation nearly $20 \%$ ) and between sheep (coefficient of variation more than $25 \%$ ). The resting salivary inflow rate was also found to fluctuate considerably.

4. During feeding, the salivary inflow rate increased; there was usually both an expansion of rumen volume and an increased rate of outflow. There was no evidence of diffusion of water from the blood into the rumen.

5. Following eating, return to resting conditions was slow.

6. When the sheep drank, there was an expansion of the rumen volume and usually an increased outflow rate. The rate of absorption of water from the rumen increased slightly, but only for a short time. Occasionally after drinking it was found that rumen marker concentrations were slightly higher than expected probably because a small part of the imbibed water bypassed the rumen down the reticular groove into the omasum.

7. Most of the water drunk in a day was consumed in a few minutes. Compared with this rapid rate of drinking, the rate of absorption of water from the rumen was always a very slow process; this finding is in disagreement with recent views expressed in the literature. However, when considered over the whole day, the amount of water absorbed from the rumen may have been approximately equal to the amount of water drunk.

8. During periods of both feeding and drinking, the mean outflow rate was about $0.7 \mathrm{l} . / \mathrm{h}$ in several series of experiments.

9. When sheep were held without food or water past their normal time for eating and drinking, the net inflow rate into the rumen soon started to decrease, but there was no immediate effect on rumen volume.

ro. 'The present work reveals the potential usefulness of the soluble marker technique in defining the changing patterns of fluid movement in the rumen throughout the day.

Numerous reports attest to the usefulness of soluble marker substances in studying the physiology of the rumen. The marker technique has been used to study, inter alia, movements of water or digesta (Hyden, I961a; Hogan, I964; Hutton, Hughes, Newth \& Watanabe, I964; Ulyatt, I964; Tulloh, Hughes \& Newth, I965; Ternouth, I967); metabolites (Murray, Reid \& Sutherland, 1962); electrolytes (Hydén, I96 i $b$; Reid, 1965; Stacy \& Warner, 1966) and micro-organisms (Warner, 1966). Despite its variety of uses, the technique has possibilities that have not been fully explored.

In the preceding paper (Warner \& Stacy, 1968) we showed that even in non-steady-

* Paper no. I : Br. F. Nutr. (1968), 22, 369. 
state conditions balances of water in the rumen could, in some circumstances, be measured with reasonable accuracy. Advantage of this fact has been taken in the present paper and the marker technique has been applied to the study of water movements in the rumen at all stages of the feeding cycle in sheep fed a restricted ration.

\section{EXPERIMENTAL}

\section{Sheep and diets}

Thirteen Merino ewes and three English-Leicester $\times$ Merino wethers were used; seven of the Merinos were those described by Warner \& Stacy (1968). Four sheep were provided with oesophageal fistulas (McManus, Arnold \& Hamilton, 1962; Stacy \& Warner, 1966).

Some of the sheep were classified as fast eaters; they consumed all the ration within $\mathrm{I} h$, and their normal regime has been described by Warner \& Stacy (I968). Other sheep were classified as slow eaters; they took 2-4 $h$ to eat all their food. Their normal regime was for food and water to be available for $4 \mathrm{~h}$, starting at noon. On experimental days they were given only their food at noon; $\mathrm{I} h$ later, they had consumed 250-400 $\mathrm{g}$ and the remaining food was removed. Water was withheld throughout this period on experimental days.

The diets were mixtures of equal parts of lucerne chaff and wheaten chaff $(\mathrm{Rg})$ and of lucerne chaff and oats $\left(\mathrm{M}_{2}\right)$. They were given in amounts of $700 \mathrm{~g}$ and supplemented with $10 \mathrm{~g} \mathrm{NaCl}$ daily. The voluntary consumption of these diets would probably have been about double the amounts given.

All sheep were well accustomed to their diets and the experimental routine.

\section{Marker techniques}

Details of the source, mode of administration and measurement of the marker, the ${ }^{51} \mathrm{Cr}$ complex of ethylenediamine tetra-acetic acid $\left({ }^{51} \mathrm{Cr}\right.$ EDTA), and of the equations used to calculate flow rates etc. have been given in the preceding paper (Warner \& Stacy, 1968). For any given set of experimental results the choice of the appropriate equation was governed by the criteria described in that paper. The results indicated that the dilution rate was constant within each resting, post-feeding or post-drinking period; it has been assumed that any changes in volume occurred at constant rates except during periods of fast eating or drinking.

Osmotic pressures were measured by the method described by Warner \& Stacy (1965).

\section{Statistical analyses}

It was found that in general the values for each parameter varied considerably both between days (within sheep) $\left(\sigma^{2}\right)$ and between sheep means $\left(\sigma_{m}^{2}\right)$. These variance components were determined by analysis of variance (Dixon \& Massey, I957, table 10-3 as modified by p. 176). To illustrate the variability, values for some individual sheep are listed in many of the tables. Since different numbers of replications were used for the various sheep, a special procedure was necessary to obtain the 'best' estimate of 
the mean $\mu$ over all sheep. H. Weiler (personal communication) has shown that the linear unbiased minimum variance estimator of $\mu$ is given by

$$
\hat{\mu}=\Sigma \lambda_{i} \bar{x}_{i} / \Sigma \lambda_{i}, \lambda_{i}=\left(\sigma_{m}^{2}+\sigma^{2} / n_{i}\right)^{-1},
$$

where $\overline{\mathrm{x}}_{i}$ is the arithmetic mean of the $\mathrm{n}_{i}$ observations from the $i$ th sheep. The variance of $\hat{\mu}$ is $\mathrm{r} / \Sigma \lambda_{i}$. The estimator $\tilde{\mu}$ obtained when in the above equation the variance components $\sigma^{2}$ and $\sigma_{m}^{2}$ are replaced by their estimates has a mean and can be shown to be unbiased provided that $\sigma_{m}^{2}$ is replaced by zero whenever its estimate turns out to be negative. In the latter instance $\hat{\mu}$ reduces to the arithmetic mean $\bar{x}$ of all individual observations.

\section{RESULTS}

When a single large dose of ${ }^{51} \mathrm{Cr}$ EDTA was given to sheep, the marker was diluted at rates indicated by the curves in Fig. I. A number of distinct periods could be demarcated on the basis of dilution rate. There was a 'resting period', so defined because the animal appeared to be in a resting state, having recovered from the effects of its last meal, and being relatively undisturbed by the absence of food or water. This period, in various experiments, lasted Io- 15 h. Feeding caused a rapid drop in marker concentration, and an even more rapid fall was seen after drinking. Following completion of either feeding or drinking or, as in Fig. 1, a combination of both, the rate of dilution of marker was less than the resting value; this period was called 'postprandial'. Sometimes (e.g. sheep 2523 in Fig. I) the difference was small; but at other times it was marked; occasionally it was found that for several hours in a post-prandial period there was very little change in the concentration of the marker, and on a few occasions, following a copious drink, the concentration even rose slightly. When the animal was not given any food or water, the marker dilution rate declined, and the effect was noticeable sometimes a little before or sometimes (Fig. I) a little after the normal time of feeding. This was called the 'starving' period.

These different periods are examined in detail in subsequent sections of this paper. The resting period has been examined towards its end, from about $4 \mathrm{~h}$ before the normal feeding time. Feeding was usually separated from drinking, so that a separate post-feeding period has been recognized. The sheep had restricted access to water and normally drank $90-100 \%$ of their total intake immediately at a rate of about $0.51 . / \mathrm{min}$, and if they drank any more they usually did so within the next $15-30 \mathrm{~min}$. In experiments designed to study events after drinking, access to water was allowed only for the time needed to complete the first large drink. Conditions in the rumen change too rapidly during actual drinking for measurements of marker concentration to be meaningful. However, experience showed that smooth marker concentration curves could be obtained by the end of the $\mathrm{I} h$ period allotted for drinking. This whole hourly interval was termed the drinking period; it was assumed that the water was consumed and mixed with the rumen contents instantaneously. The post-drinking period was then the time needed for the gradual dissipation of the major effects of the imbibed water; the definition may be extended to include water injected into the rumen. 


\section{Resting period}

Sixteen sheep were maintained on the normal regime mentioned above, and estimates of the resting volume and net inflow rates were made (Table I). Three sheep were regularly fed the diet $\mathrm{M}_{2}$ and eleven the diet $\mathrm{R}_{9}$, and in the other two animals the effects were observed of changing from one diet to the other. The average volume of water in the ruminoreticulum (rumen volume) of these sheep was about 3.91 , constituting about $10 \%$ of the body-weight. The average dilution rate was $0.077 \mathrm{~h}^{-1}$,

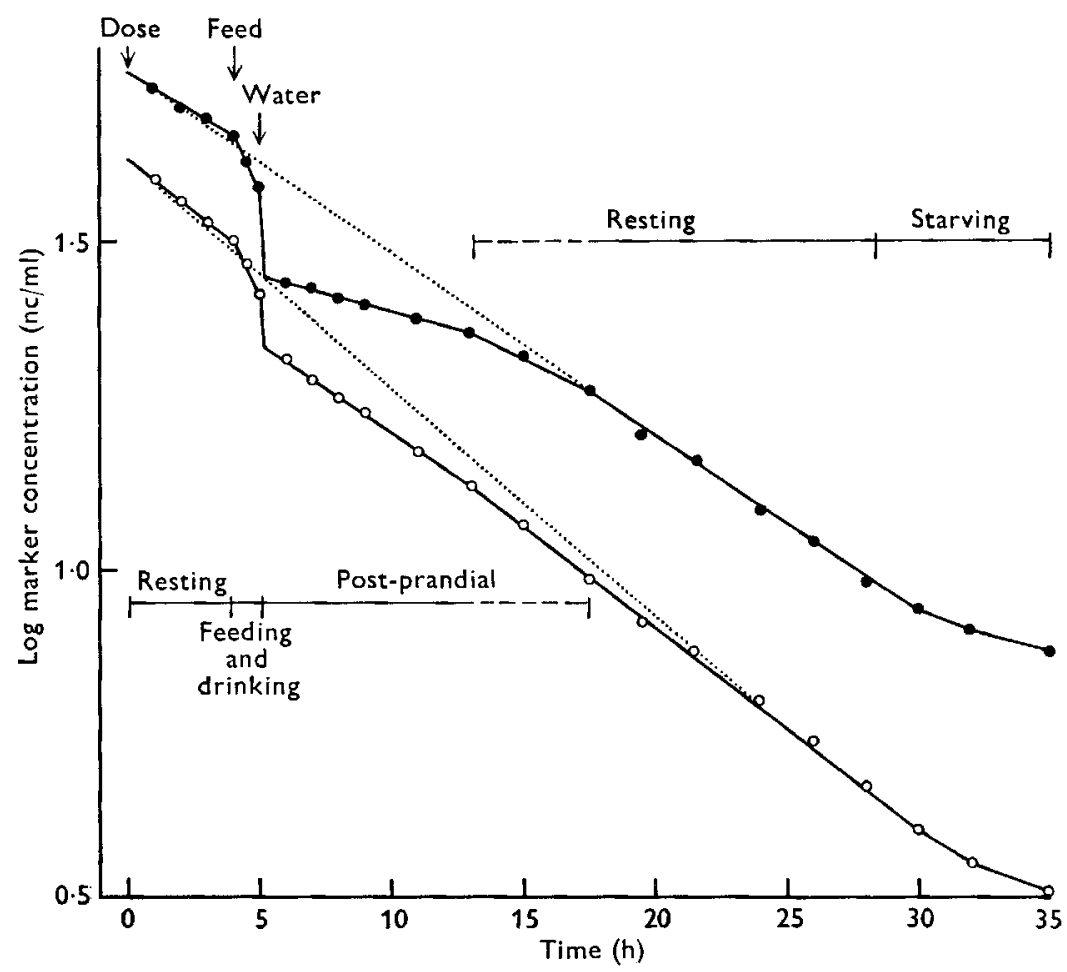

Fig. $x$. The dilution of ${ }^{51} \mathrm{Cr}$ EDTA in the rumen during a normal feeding cycle. Sheep 2606 ( ), given the diet $\mathrm{M}_{2}$, and sheep $2_{523}(\mathrm{O})$, given the diet $\mathrm{R}_{9}$, consumed about $500 \mathrm{~g}$ food during the hour and drank about $\mathrm{I}^{\prime} 5 \mathrm{l}$. water immediately it was presented. As indicated on the graph, it is assumed that the imbibed water is immediately mixed throughout the rumen contents and that the rate of dilution of marker is steady thereafter. The dotted lines show the average $(24 \mathrm{~h})$ dilution rate.

corresponding to a marker half-time of $9 \mathrm{~h}$, or mean retention time (the mean time the marker molecules spent in the rumen) of $13 \mathrm{~h}$. The average net inflow rate was about $0.31 . / \mathrm{h}$.

In five experiments on two sheep with oesophageal fistulas, which had resting rumen volumes and flow rates similar to the average values shown in Table $\mathrm{I}$, the rate of flow of saliva was determined in the last hour only of the $3.5 \mathrm{~h}$ period used to measure the resting volume and dilution rate. In two of these experiments the calculated rate of absorption was negative, i.e. water appeared to enter the rumen against its concentra- 
tion gradient; it is thought that this was an artifact attributable to the kind of variation in salivary flow rate illustrated in Fig. 2. The average rate of absorption of water $( \pm \mathrm{SE}$ ) in the five experiments was $0.02 \pm 0.021 . / \mathrm{h}$. The salivary flow and absorption rates of two other sheep were examined over the whole $3.5 \mathrm{~h}$, and the results are given later (see Table 8). The average resting rate of absorption of water from the rumen into the blood was $0.08 \pm 0.021$. $/ \mathrm{h}$. While these sheep had smaller resting rumen volumes and lower flow rates than the average found above (Table I), it seems unlikely that the rate of absorption was unusually low. The over-all average rate of absorption was therefore about $0.051 . / \mathrm{h}$.

\section{Table I. Rumen volume and flow rate under resting conditions: average values together with values for some individual sheep}

(A total of seventy-four observations were made on sixteen sheep, except for body-weight which was measured once only for each sheep)

\begin{tabular}{|c|c|c|c|c|c|c|c|}
\hline & \multirow{2}{*}{$\begin{array}{l}\text { Overall } \\
\text { mean } \\
(\mu) \pm \mathrm{SE}\end{array}$} & \multirow{2}{*}{$\begin{array}{l}\text { SD } \\
\text { within } \\
\text { sheep } \\
(\sigma)\end{array}$} & \multirow{2}{*}{$\begin{array}{c}\text { SD } \\
\text { between } \\
\text { sheep } \\
\text { means } \\
\left(\sigma_{m}\right)\end{array}$} & \multicolumn{4}{|c|}{ Values for some individual sheep } \\
\hline & & & & 2503 & 2508 & 2520 & 2523 \\
\hline No. of observations & 74 & - & - & 3 & 15 & 6 & 9 \\
\hline Body-weight (kg) & $39 \pm 1 *$ & - & $5^{*}$ & 46 & 42 & 37 & 47 \\
\hline $\begin{array}{l}\text { Rumen volume (1.) } \\
\text { Volume }\end{array}$ & $3.88 \pm 0.21$ & 0.55 & 0.77 & $2 \cdot 74$ & $3-92$ & 4.58 & $4: 33$ \\
\hline $\begin{array}{l}\text { (\% of body-weight) } \\
\text { Dilution rate }\left(h^{-1}\right) \\
\text { Net inflow rate }(1 . / h)\end{array}$ & $\begin{array}{c}10.1 \pm 0.8^{*} \\
0.077 \pm 0.006 \\
0.29 \pm 0.02\end{array}$ & $\begin{array}{l}-\overline{0} \\
0.020 \\
0.05\end{array}$ & $\begin{array}{l}3^{*} \\
0.022 \\
0.08\end{array}$ & $\begin{array}{l}6 \\
0.081 \\
0.22\end{array}$ & $\begin{array}{l}9.3 \\
0.067 \\
0.26\end{array}$ & $\begin{array}{l}12.4 \\
0.038 \\
0.17\end{array}$ & $\begin{array}{l}9.2 \\
0.087 \\
0.38\end{array}$ \\
\hline
\end{tabular}

* Simple mean with standard error, with standard deviation of observations.

Over the several months when the measurements were made it was found that individual animals exhibited considerable variation in their resting rumen volume and flow rate. The variation was irregular and unpredictable; there was no correlation between volume and net inflow rate (for sheep 2508 with the greatest number of observations $r=-0.08, P>0.7)$. The differences between sheep were also considerable and were often statistically highly significant. Again, no regularities were noticed, there being no significant correlations between any of the parameters in Table I.

The values in Table I show the overall mean for seventy-four experiments on sixteen sheep, and results for some individual animals have been included to emphasize the sort of differences that may exist between sheep. For instance sheep $\mathbf{2 5 2 3}$ and 2503 had similar body-weights and dilution rates but their rumen volumes and net inflow rates were distinctly different. Similarly, sheep 2508, 2520 and 2523 had fairly similar rumen volumes but differed in other measurements. No consistent differences in the values for resting volume or flow rates could be seen between the fast and the slow eaters, nor between sheep fed $R_{9}$ and those fed $M_{2}$.

It is possible that most of the variation in the net inflow rate (Table $\mathrm{r}$ ) was caused by fluctuations in salivary secretion rates. To investigate this possibility, two series of experiments were carried out using sheep fitted with oesophageal fistulas. After collec- 
tion at set intervals, the saliva was measured and poured into the rumen via a rumen fistula. In the first series, saliva was collected and measured at 5 min intervals; considerable variation, up to about twofold, was noted in the rate of secretion (Fig. 2). To check that none of this variation was due to irregular flow past the fistula into the rumen, entry to the rumen was blocked by the inflation of a balloon in the oesophagus below the fistula. The presence of the balloon did not appear to have any remarkable effect on the salivary flow rate. In the second series of experiments, saliva was collected over consecutive 30 min periods; the results are also shown in Fig. 2. Both within and between sheep the rate of salivary secretion varied by about twofold.
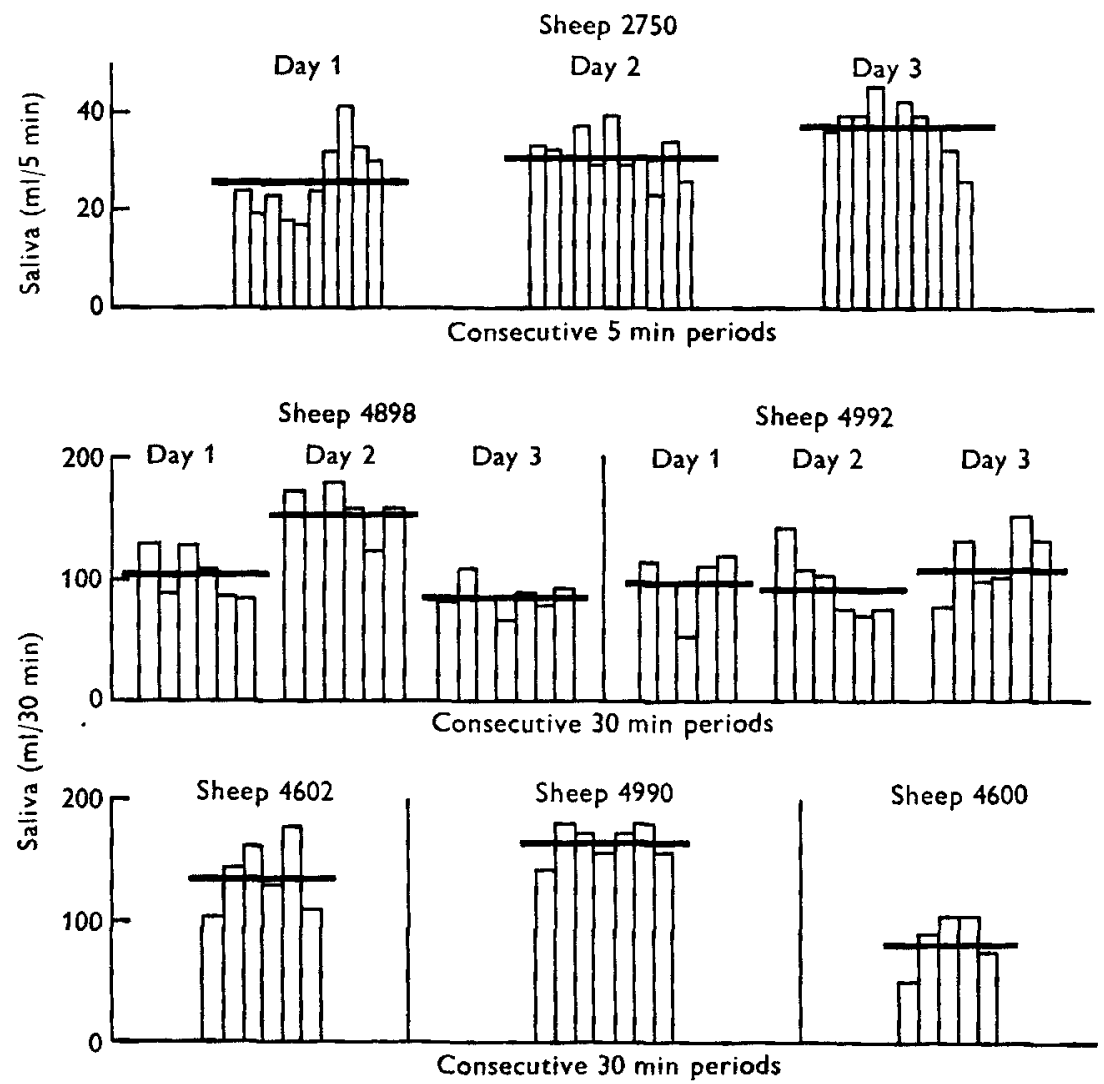

Fig. 2. Saliva production of resting sheep in consecutive $5 \mathrm{~min}$ (top row) or $30 \mathrm{~min}$ (bottom two rows) periods. The mean rate of production is indicated by the horizontal line. On day 2 , a balloon was inserted into the oesophagus of sheep 2750 distal to the fistula.

\section{Feeding period}

Doses of marker were given about $4 \mathrm{~h}$ before and $\mathrm{I} h$ after commencement of feeding. A marked increase in dilution rate was found while the animal was eating (Fig. 3, Tables 2, 3). Sometimes, and particularly when the sheep failed to eat all its food in the allotted time, the dilution rate appeared to be constant throughout the feeding hour. More frequently, the dilution rate was greatest at the beginning and 
declined to a lower value at the end of the meal (Fig. 3); mixing in the rumen was usually sufficient to give a smooth curve throughout the period of eating.

In a few experiments, exemplified in Fig. 3, food consumption was measured at intervals. It was found that the dilution rate followed the rate of consumption of food, that is the net rate of inflow of water bore a fairly constant relation to the rate of food consumption. In these experiments, the rate of eating was slower than usual, and the overall average dilution rate was lower, presumably due to the interruptions caused by the repeated removal and weighing of food.

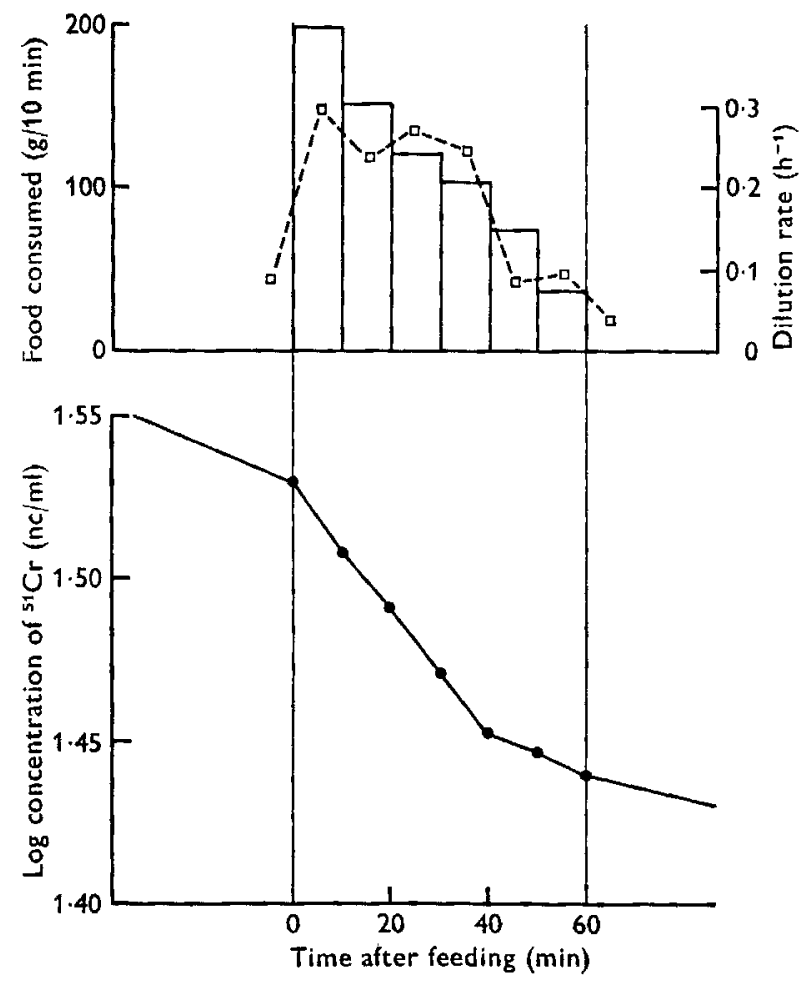

Fig. 3. Concentration of ${ }^{51} \mathrm{Cr} \operatorname{EDTA}(\bullet)$, dilution rate $(\square)$, and rate of consumption of food (histograms) during eating. The experimental points determining the slope of the marker concentration curve before and after feeding are not shown (sheep 2606, diet $\mathrm{M} 2$ ).

Table 2 shows some of the results from thirty experiments with the rapid eaters. Individual animals varied from time to time but there were also characteristic differences between animals. The major response to feeding was a large increase in the net inflow of water.

It may be seen in Table 2 that in response to the increased inflow the sheep expanded their rumen volume or increased the rate of outflow of fluid to the omasum. Some animals seemed inclined to do one thing, some the other and some both. Sheep 2606 (Table 2) characteristically expanded its rumen volume but did not increase, and perhaps even decreased, its outflow rate. On the other hand, sheep 2523 showed little 
change in rumen volume, while changes in both measurements were observed in the other sheep.

Following feeding, the net inflow was reduced below the resting rate (Table 2).

Values for sheep classified as slow eaters are shown in Table 3. They ate only about $300 \mathrm{~g}$ food within the allotted hour, and as expected, there was a smaller increase in the inflow of water. However, the average outflow rate was similar to that of the fast

Table 2. Water balances in the rumen of sheep that ate rapidly: average values together with values for some individual sheep

(A total of thirty observations were made on seven sheep. The resting period lasted $3.75 \mathrm{~h}$, the feeding period $\mathrm{I} \cdot \mathrm{O} \mathrm{h}$ and the post-feeding period $3.5 \mathrm{~h}$ )

\begin{tabular}{|c|c|c|c|c|c|c|c|}
\hline & \multirow{2}{*}{$\begin{array}{l}\text { Overall } \\
\text { mean } \\
(\mu) \pm \mathrm{SE}\end{array}$} & \multirow{2}{*}{$\begin{array}{l}\text { SD } \\
\text { within } \\
\text { sheep } \\
(\sigma)\end{array}$} & \multirow{2}{*}{$\begin{array}{c}\text { SD } \\
\text { between } \\
\text { sheep } \\
\text { means } \\
\left(\sigma_{m}\right)\end{array}$} & \multicolumn{4}{|c|}{$\begin{array}{l}\text { Values for some } \\
\text { individual sheep }\end{array}$} \\
\hline & & & & 2508 & 2520 & 2523 & 2606 \\
\hline No. of observations & 30 & - & - & 12 & 3 & 7 & 3 \\
\hline $\begin{array}{cl}\text { Rumen } & \text { Initial } \\
\text { volume (1.): Expansion } & \text { on feeding* }\end{array}$ & $\begin{array}{l}3.92 \pm 0.23 \\
0.53 \pm 0.11\end{array}$ & $\begin{array}{l}0.62 \\
0.38\end{array}$ & $\begin{array}{l}0.47 \\
0.20\end{array}$ & $\begin{array}{l}3.89 \\
0.72\end{array}$ & $\begin{array}{l}4.58 \\
0.67\end{array}$ & $\begin{array}{l}4 \cdot 25 \\
0 \cdot 22\end{array}$ & $\begin{array}{l}3.17 \\
0.79\end{array}$ \\
\hline $\begin{array}{cl}\text { Dilution rate } & \text { Resting } \\
\left(\mathrm{h}^{-1}\right): & \text { Feeding } \\
& \text { Post-feeding }\end{array}$ & $\begin{array}{l}0.072 \pm 0.007 \\
0.293 \pm 0.020 \\
0.048 \pm 0.008\end{array}$ & $\begin{array}{l}0.015 \\
0.054 \\
0.022\end{array}$ & $\begin{array}{l}0.015 \\
0.044 \\
0.016\end{array}$ & $\begin{array}{l}0.068 \\
0.298 \\
0.040\end{array}$ & $\begin{array}{l}0.034 \\
0.348 \\
0.025\end{array}$ & $\begin{array}{l}0.087 \\
0.233 \\
0.074\end{array}$ & $\begin{array}{l}0.083 \\
0.288 \\
0.036\end{array}$ \\
\hline $\begin{array}{l}\text { Resting } \\
\text { Feeding } \\
\text { Post-feedingt } \\
\text { Overall } \\
\text { decrease }\end{array}$ & $\begin{array}{l}0.28 \pm 0.03 \\
1.20 \pm 0.09 \\
0.20 \pm 0.03 \\
0.07 \pm 0.02\end{array}$ & $\begin{array}{l}0.04 \\
0.15 \\
0.07 \\
0.10\end{array}$ & $\begin{array}{l}0.07 \\
0.23 \\
0.06 \\
\$\end{array}$ & $\begin{array}{l}0.26 \\
I \cdot 28 \\
0.17 \\
0.08\end{array}$ & $\begin{array}{l}0.15 \\
I .83 \\
0.13 \\
0.02\end{array}$ & $\begin{array}{l}0.37 \\
1.02 \\
0.31 \\
0.05\end{array}$ & $\begin{array}{l}0.26 \\
I \cdot 01 \\
0 \cdot 14 \\
0.12\end{array}$ \\
\hline $\begin{array}{cl}\text { Outflow rate } & \text { Resting* } \\
(\mathrm{l} / \mathrm{h}): & \text { Feeding }\end{array}$ & $\begin{array}{l}0.26 \pm 0.03 \\
0.71 \pm 0.12\end{array}$ & $\begin{array}{l}0.04 \\
0.47\end{array}$ & $\begin{array}{l}0.07 \\
0.20\end{array}$ & $\begin{array}{l}0.24 \\
0.56\end{array}$ & $\begin{array}{l}0.13 \\
1 \cdot 16\end{array}$ & $\begin{array}{l}0.35 \\
0.80\end{array}$ & $\begin{array}{l}0.24 \\
0.22\end{array}$ \\
\hline
\end{tabular}

* Calculated on the assumption that the volume expanded during the resting period by $0.09 \mathrm{I}$. (Table 9).

$\dagger$ Calculated on the assumption that the rumen volume was constant during the post-feeding period. If the volume was contracting at the rate found in Table 4, then the figures given would overestimate the true values by 0.01 to $0.021 . / \mathrm{h}$; values in the next row would also be affected.

I Values calculated from the original values, not the means.

$\S$ Variance calculated as negative: see p. 391 .

eaters, so that the expansion of rumen volume was much less; indeed, in two sheep there was a characteristic reduction in rumen volume following feeding. In one of these sheep, $275^{\circ}$ with an oesophageal fistula (Table 3), the volume of saliva nearly equalled the calculated net inflow of water, so that there was little movement of water across the rumen wall.

Both in $275^{\circ}$ and in another sheep with an oesophageal fistula (not otherwise used in this work) the flow of saliva depended on the rate of food consumption (see also Stacy \& Warner, 1966), and it was found on average that $2.7 \pm 0.2 \mathrm{ml}$ saliva was secreted per $g$ dry matter eaten. Assuming that the enhanced rates of saliva production. during eating were similar in the other slow eaters, it can be seen in Table 3 that virtually all of the fluid inflow to the rumen in the feeding period could be attributed to saliva. The evidence did not suggest that there was any significant net movement of 
water across the rumen wall. It appeared that the above figure for saliva secretion did not apply to the fast eaters, because at this rate of secretion more water would have been secreted into the rumen than was indicated by the dilution rate of the marker. For this to be true it would have been necessary to assume that water was absorbed from the rumen against its concentration gradient, which was held to be particularly unlikely since the rumen osmotic pressure in these sheep rose during the feeding period to higher levels (400-500 m-osmoles $/ \mathrm{kg})$ than in the slow eaters $\left(35^{\circ}-45^{\circ} \mathrm{m}\right.$-osmoles $\left./ \mathrm{kg}\right)$. It was thus far more feasible to assume instead that the fast eaters produced less saliva

Table 3. Water balances in the rumen of sheep that ate slowly: average values together with values from some individual sheep

(A total of nine observations were made on five sheep. The resting period lasted $4.0 \mathrm{~h}$, the feeding period $\mathrm{I} \cdot \mathrm{O} \mathrm{h}$ and the post-feeding period $4.0 \mathrm{~h}$ )

\begin{tabular}{|c|c|c|c|c|c|c|}
\hline & & Overall & $\begin{array}{l}\text { SD } \\
\text { within }\end{array}$ & $\begin{array}{c}\text { SD } \\
\text { between } \\
\text { sheep } \\
\text { means }\end{array}$ & $\begin{array}{l}\text { Values } \\
\text { indivic }\end{array}$ & $\begin{array}{l}\text { or some } \\
\text { al sheep }\end{array}$ \\
\hline & & $(\mu) \pm \mathrm{SE}$ & $(\sigma)$ & $\left(\sigma_{m}\right)$ & 2714 & $275^{\circ}$ \\
\hline No. of observations & & 9 & 一 & - & 2 & 3 \\
\hline Rumen volume (1.) & $\begin{array}{l}\text { Initial } \\
\text { Expansion* } \\
\text { on feeding }\end{array}$ & $\begin{array}{l}3.78 \pm 017 \\
0.06 \pm 0.20\end{array}$ & $\begin{array}{l}0.15 \\
0.20\end{array}$ & $\begin{array}{l}0.36 \\
0.40\end{array}$ & $\begin{array}{l}4.04 \\
0.59\end{array}$ & $\begin{array}{r}3.88 \\
-0.25\end{array}$ \\
\hline Dilution rate $\left(\mathrm{h}^{-1}\right)$ : & $\begin{array}{l}\text { Resting } \\
\text { Feeding } \\
\text { Post-feeding }\end{array}$ & $\begin{array}{l}0.079 \pm 0.008 \\
0.206 \pm 0.014 \\
0.058 \pm 0.011\end{array}$ & $\begin{array}{l}p \cdot 015 \\
0.043 \\
0.028\end{array}$ & $\begin{array}{c}0.014 \\
+ \\
0.015\end{array}$ & $\begin{array}{l}0.056 \\
0.175 \\
0.020\end{array}$ & $\begin{array}{l}0.096 \\
0.217 \\
0.079\end{array}$ \\
\hline $\begin{array}{l}\text { Net inflow rate } \\
(1 . / \mathrm{h}) \text { : }\end{array}$ & $\begin{array}{l}\text { Resting* } \\
\text { Feeding } \\
\text { Post-feeding* } \\
\text { Overall } \\
\text { decreasef }\end{array}$ & $\begin{array}{l}0.29 \pm 0.03 \\
0.77 \pm 0.05 \\
0.21 \pm 0.04 \\
0.09 \pm 0.02\end{array}$ & $\begin{array}{l}0.05 \\
0.15 \\
0.09 \\
0.05\end{array}$ & $\begin{array}{c}0.05 \\
t \\
0.04 \\
t\end{array}$ & $\begin{array}{l}0.23 \\
0.75 \\
0.09 \\
0.14\end{array}$ & $\begin{array}{l}0.37 \\
0.81 \\
0.28 \\
0.09\end{array}$ \\
\hline $\begin{array}{l}\text { Salivary inflow } \\
\text { rate }(1 . / \mathrm{h}) \text { : }\end{array}$ & Feeding $\S$ & $0.78 \pm 0.07$ & 0.21 & $\dagger$ & 0.73 & 0.78 \\
\hline $\begin{array}{l}\text { Absorption rate } \\
(1 . / \mathrm{h}) \text { : }\end{array}$ & Feeding & $0.02 \pm 0.05$ & 0.15 & $t$ & -0.02 & -0.04 \\
\hline Outflow rate $(1 . / h)$ : & $\begin{array}{l}\text { Resting* } \\
\text { Feeding }\end{array}$ & $\begin{array}{l}0.29 \pm 0.03 \\
0.71 \pm 0.20\end{array}$ & $\begin{array}{l}0.05 \\
0.22\end{array}$ & $\begin{array}{l}0.05 \\
0.42\end{array}$ & $\begin{array}{l}0.23 \\
0.17\end{array}$ & $\begin{array}{l}0.37 \\
1.06\end{array}$ \\
\hline
\end{tabular}

* Calculated on the assumption that the rumen volume was constant in resting and post-feeding periods.

$\dagger$ Variance calculated as negative: see p. 391 .

Values calculated from the original values, not the means.

$\$$ Value measured for sheep 2750 , which had an aesophageal fistula. This corresponded to $2.7 \mathrm{ml}$ saliva/g food consumed, and this figure was used to calculate salivation rates for the other sheep.

per $g$ of food than the slow eaters. Just how much less it was not possible to say since the sheep with oesophageal fistulas could not be induced to eat all their food in an hour.

Again, the net inflow rate following feeding was reduced below the resting rate (Table 3). 


\section{Post-feeding period}

It was noticed above (Tables 2,3 ) that the net inflow rate was lower in the postfeeding period than in the resting period. Some experiments were carried out in which a third dose of marker was given $5.5 \mathrm{~h}$ after commencement of feeding, and the results are shown in Table 4. It can be seen that the outflow rate during the post-feeding

Table 4. After-effects of feeding on the rumen water balances of sheep: average values together with values for individual animals

(A total of seven observations were made on three sheep. The resting period lasted $3.75 \mathrm{~h}$, the feeding period $\mathrm{I} \cdot \mathrm{O} \mathrm{h}$, the post-feeding period $4.5 \mathrm{~h}$ and the final period $4.0 \mathrm{~h}$ )

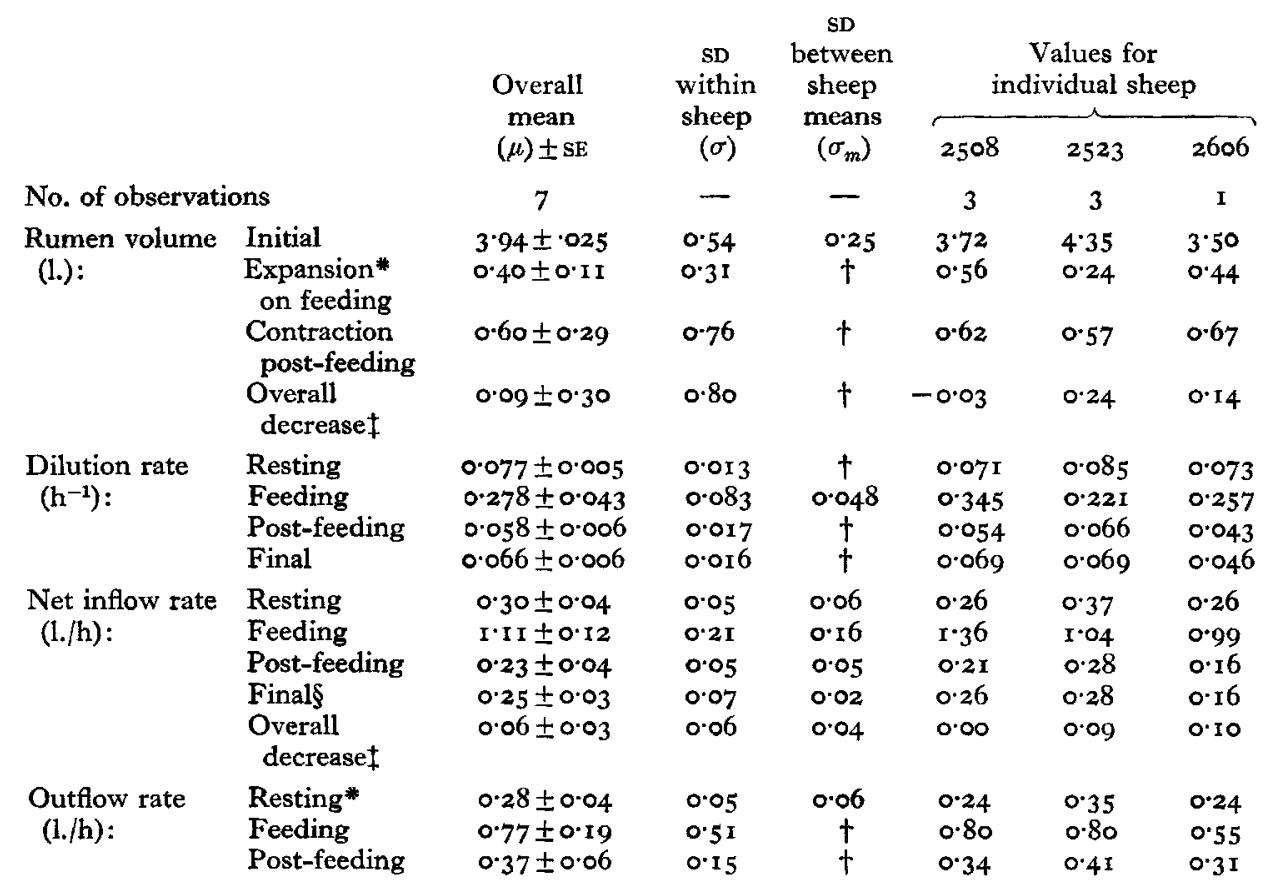

* Calculated on the assumption that the volume expanded during the resting period by 0.091 . (Table 9).

$\dagger$ Variance calculated as negative: see p. $39 \mathrm{r}$.

Values calculated from the original values, not the means.

$\$$ Calculated on the assumption that the rumen volume was constant in the final period.

period remained somewhat elevated above the resting value. This, combined with the lowered net inflow rate, resulted in a contraction of rumen volume. Although there was much variation between experiments, the rumen volume on average had returned to approximately its resting value by $5.5 \mathrm{~h}$ after commencement of feeding. During the subsequent $4 \mathrm{~h}$, the net inflow rate increased to about its previous resting value in one of the three sheep examined. It is presumed that the net inflow rates for the other sheep would have shown similar increases shortly after conclusion of the experiment. 


\section{Drinking period}

Initially, experiments were done in conjunction with those described in Tables 2 and 4. Water was presented $4.5 \mathrm{~h}$ after commencement of feeding and a dose of marker was given $\mathrm{I} \cdot \mathrm{O} \mathrm{h}$ later. It was hoped that the rumen volume before drinking could be calculated from the volume measured immediately after eating, but it became clear that the changes were too variable to permit a reliable estimate to be made ('Table 4). A different approach was therefore adopted and the rumen volume before drinking was calculated from the reduction in marker concentration caused by the entry of the known volume of water that was drunk. In seven of twenty experiments

\section{Table 5. Calculated water balances in the rumen during the drinking hour}

(Values for sheep 2508 fed $4.5 \mathrm{~h}$ before water was given; the water was consumed in about $3 \mathrm{~min}$ )

\begin{tabular}{|c|c|}
\hline$V_{1}$ & Resting rumen volume (1.) \\
\hline$V_{2}$ & Post-feeding rumen volume (1.) \\
\hline$V_{4}$ & Post-drinking rumen volume (I.) \\
\hline$F_{2}$ & Post-feeding net inflow rate $(1 . / \mathrm{h})^{*}$ \\
\hline$F_{4}$ & Post-drinking net inflow rate $(1 . / \mathrm{h})^{*}$ \\
\hline$I$ & Water drunk (1.) \\
\hline$G$ & $\begin{array}{l}\text { Assumed volume bypassing rumen or } \\
\text { absorbed during drinking hour (1.) } \dagger\end{array}$ \\
\hline$V_{\mathbf{3}}$ & $\begin{array}{l}\text { Pre-drinking rumen volume (l.) } \\
\left(V_{3}=(I-G) c_{w} /\left(c_{3}-c_{w}\right)\right) \ddagger\end{array}$ \\
\hline$V_{2}-V_{3}$ & $\begin{array}{l}\text { Post-feeding contraction in rumen } \\
\text { volume (1.) }\end{array}$ \\
\hline$V_{4}-V_{3}$ & $\begin{array}{l}\text { Expansion in rumen volume during } \\
\text { drinking period (I.) }\end{array}$ \\
\hline$E_{3}$ & $\begin{array}{l}\text { Outflow in drinking period } \\
\left(E_{3}=\left(c_{3} V_{3}-c_{4} V_{4}\right) / \bar{c}\right) \pm(1 .)\end{array}$ \\
\hline
\end{tabular}

$\begin{array}{cccc}4.62 & & & \\ 5.06 & & & \\ 6.28 & & & \\ 0.21 & & & \\ 0.10 & & & \\ 1.88 & & & \\ 0.0 & 0.6 & 0.7 & 0.8 \\ 8.8 & 6.1 & 5.6 & 5.1 \\ -3.7 & -1.0 & -0.5 & 0.0 \\ -2.5 & 0.2 & 0.7 & 1.2 \\ 4.5 & 1.2 & 0.6 & 0.0\end{array}$

* Calculated on the assumption that the rumen volume $\left(V_{2}\right.$ or $\left.V_{4}\right)$ was constant in the period concerned.

$\dagger$ It is held that the value giving most reasonable conclusions lies between 0.7 and 0.81 .

The marker concentration curve was extrapolated backwards during the drinking period; $c_{w}$ was then the calculated concentration immediately after consumption of the water and $\bar{c}$ the mean value between that point and the end of the period; $c_{3}$ and $c_{4}$ were the marker concentrations just before and at the end of the drinking period. This calculation assumes that the whole of $G$ bypassed the rumen. It can readily be shown that, if the whole of $G$ were absorbed, then the value of $V_{3}-E_{3}$ would be the same as indicated above and the individual values for $V_{3}$ and $E_{3}$ would not differ markedly from those above.

on six sheep the results appeared reasonable, that is, the calculated change in rumen volume after feeding was within the range $(+0.4$ to $-1 \cdot 01$.) previously found in the experiments summarized in Table 4 , and both the expansion in rumen volume and the outflow during the drinking period were positive but not greater than the volume of water consumed. In the remaining thirteen experiments these conditions did not hold unless it is assumed that a small proportion of the ingested water failed to affect the marker concentration in the rumen at the end of the drinking period; this may have occurred because some of the water bypassed the rumen via the reticular groove and/or was absorbed across the rumen wall during the drinking period. Only a small range of values, varying in different experiments from $0 . \mathrm{I}$ to 0.81 , gave results that met the criteria stated above. A typical example is shown in Table 5 . In that same experiment, 
it was found that the rumen osmotic pressure in the resting period was $244 \mathrm{~m}$-osmoles/ $\mathrm{kg}$; at the start and finish of the post-feeding period it was 436 and $408 \mathrm{~m}$-osmoles $/ \mathrm{kg}$, and at the start and finish of the post-drinking period it was $3 \mathrm{I} 7$ and $265 \mathrm{~m}$-osmoles $/ \mathrm{kg}$.

In another series of experiments, water was offered immediately after the feeding period, and again the pre-drinking rumen volume was calculated from the dilution of the marker. In two out of seven experiments it was again necessary for similar reasons to postulate that a small volume of water $(0.1$ to 0.31 .) either bypassed the rumen or was absorbed during the drinking period.

\section{Table 6. Feeding and drinking regime}

(Times and periods when food and water were available)

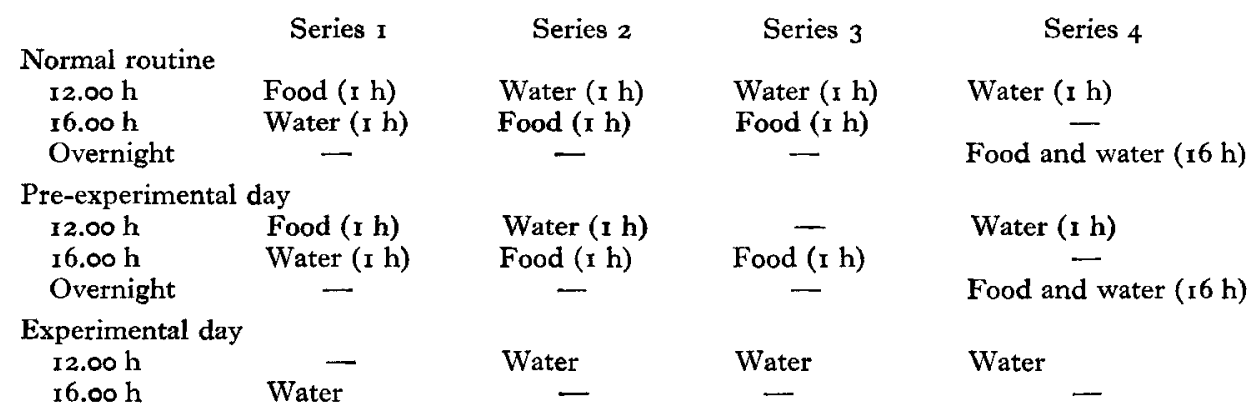

In both these series of experiments it was noticed (see, for example, Table 5) that small differences in the value assumed for the volume of water bypassing the rumen or absorbed gave large differences in the calculated pre-drinking rumen volume. Therefore there was considerable uncertainty about the estimates of change in rumen volume and of outflow during the drinking period, even though the volume of water bypassing the rumen or absorbed could usually be estimated within 0.11 . With the aim of reducing the uncertainty, attempts were made to study changes in the rumen when sheep drank during the resting period. Because of the sheep's reluctance to drink at this time, several regimes were adopted to make the animals thirsty; these are described in Table 6 and the results are shown in Table 7. The response to the consumption of water was divided between expansion of rumen volume and an increased outflow. In none of the fifteen experiments was there any evidence to suggest that a considerable quantity of water either bypassed the rumen or was absorbed across the reticulo-ruminal epithelium; any likely error in the assumptions made would not affect this conclusion.

It was found that in the experiments of series 3 (Table 6), where the sheep had been fed twice but had had no water during the $44 \mathrm{~h}$ preceding the experiment, the scatter of experimental points about the marker concentration curves was greater than usual, and several experiments had to be rejected because of this.

The entry of water, imbibed or injected, into the rumen of a sheep in the resting period caused a considerable drop in rumen marker concentration (Fig. 4). This was followed by a period of $3 \cdot 0-4 \cdot 5 \mathrm{~h}$ during which the slope of the marker concentration 


\section{Table 7. Mean water balances in the rumen in the hour immediately following drinking}

(Sheep drinking during the resting period, as described in Table 6)

No. of sheep

No. of observations

Water drunk (1.)

Expansion of rumen volume (1.)

Salivary inflow (1.) t

Outflow (1.)

Water absorbed or bypassing rumen (1.)§

$\begin{array}{cc}\text { Series I } & \text { Series 2 } \\ 2^{*} & 3^{*} \\ 2 & 4 \\ \text { I.2 } & 0.9 \\ 0.7 & 0.4 \\ 0.2 & 0.3 \\ 0.4 & 0.8 \\ 0.3 & 0.0\end{array}$

$\begin{array}{cc}\text { Series } 3 & \text { Series } 4 \\ 3^{*} & 2 \dagger \\ 6 & 3 \\ 2.3 & 1.7 \\ 1.8 & 0.9 \\ 0.3 & 0.2 \\ 0.5 & 0.8 \\ 0.3 & 0.2\end{array}$

* A total of four different sheep, drawn from the seven fast eaters of Table 2 .

$\uparrow$ Sheep with permanent diabetes insipidus, caused by hypothalamic lesions (Brook, Radford $\&$ Stacy, 1968).

$\ddagger$ Assumed to equal the net inflow rate of the immediately preceding period.

$\S$ The difference between the sum of the water drunk and salivary inflow and the sum of rumen expansion and outflow.

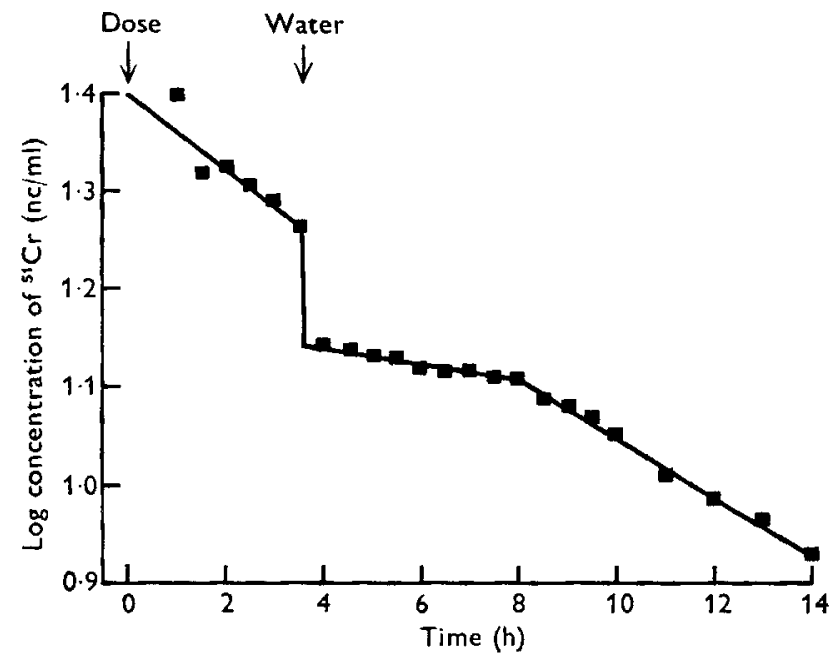

Fig. 4. Concentration of ${ }^{51} \mathrm{Cr}$ EDTA in the rumen of sheep 3197 . An injection of $1 \cdot 51$. water was given into the rumen $3.5 \mathrm{~h}$ after injecting the marker.

curve was much reduced; in some experiments, the slope was actually reversed, since the marker concentration increased slightly. In some experiments there was, at the end of this period, a fairly abrupt change of slope to a value near the resting one (Fig. 4). In other experiments, no abrupt change was noted and the final slope of the curve tended to be flatter at the end of the period than it was immediately after drinking; this pattern of response was found quite often in sheep that, by the end of the experiment, had been $30 \mathrm{~h}$ or more without food.

Two sheep with oesophageal fistulas were used to study more closely the effects of injecting water (temperature about $25^{\circ}$ ) into the rumen. Doses of marker were given $3.5 \mathrm{~h}$ before and 0.5 and $4^{\circ} \mathrm{Oh}$ after injection of the water. Subsequent work showed that the $0.5 \mathrm{~h}$ may not have been long enough for adequate mixing of the injected 
water, so that calculations of the rumen volume, and hence of outflow rate during the $0.5 \mathrm{~h}$ following injection, may have been affected. Indeed, values for the outflow rate at this time were particularly erratic and have not been included with the other results in Table 8; any error in the values for the change in rumen volume in Table 8 would not invalidate the main conclusions. In the post-injection period (Table 8), the outflow rate was little affected. The contraction in rumen volume was mainly due to a decreased salivary inflow rate and an increased absorption rate. These effects were so great in one sheep, 4992, that the net inflow rate and hence the dilution rate were

\section{Table 8. Water balances in the rumen of sheep with oesophageal fistulas after intraruminal injection of water}

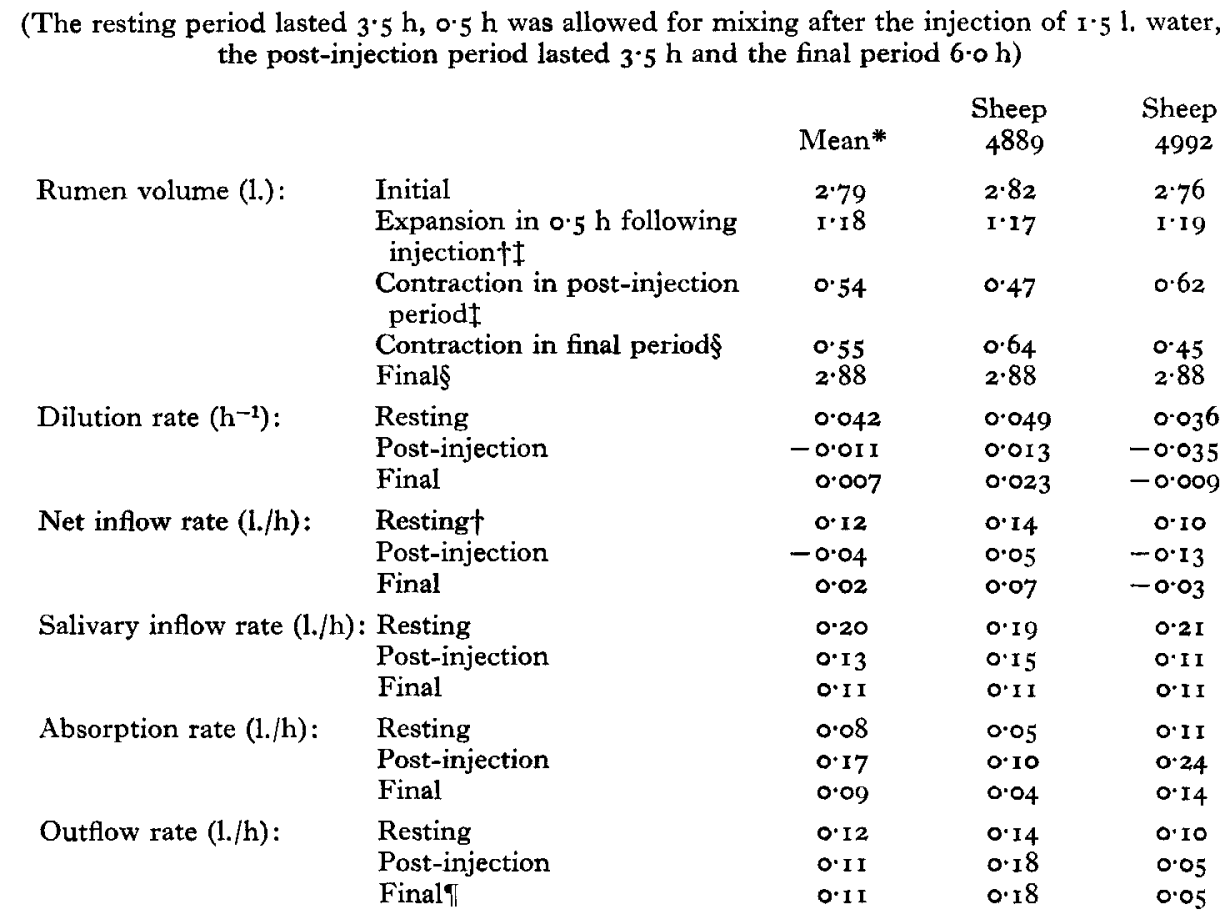

* Two experiments were performed on each sheep; differences between sheep were usually greater than differences within sheep.

+ Calculated on the assumption that the rumen volume was constant in the resting period.

\pm There is some uncertainty about these values (but not about the difference between them); see above.

$\S$ The final volume was calculated from the measured dilution rate and volume at the start of the final period and the assumed outflow rate.

I Assumed to be the same as in the post-injection period.

negative. In the final period, although the salivary inflow rate remained low, the absorption rate decreased to about the resting value. In these experiments, the osmotic pressure in the rumen fell to $150-180 \mathrm{~m}$-osmoles $/ \mathrm{kg}$ after injection of the water; it then rose by approximately $20 \mathrm{~m}$-osmoles/kg in the post-injection period (Table 8 ) and by another $30 \mathrm{~m}$-osmoles $/ \mathrm{kg}$ at the end of the experiment.

A total of forty experiments were carried out on sheep drinking at various times 
Table 9. Effects of starvation on rumen water balances

(Three doses of marker were given, 21,25 and $30 \mathrm{~h}$ after feeding ( $17,2 \mathrm{r}$ and $26 \mathrm{~h}$ after drinking). Values given are the overall averages with their standard errors for each period for nine experiments on five sheep)

$$
\begin{array}{ccc}
\begin{array}{c}
\text { Period } 2 \mathrm{I}-25 \mathrm{~h} \\
\text { after feeding }
\end{array} & \begin{array}{c}
\text { Period } 25-30 \mathrm{~h} \\
\text { after feeding }
\end{array} & \begin{array}{c}
\text { Period } 30-34 \mathrm{~h} \\
\text { after feeding }
\end{array}
\end{array}
$$

$\begin{array}{lccc}\text { Increase in rumen volume }(1 .) * & 0.09 \pm 0.08 & -0.01 \pm 0.15 & - \\ \text { Dilution rate }\left(\mathrm{h}^{-1}\right) & 0.088 \pm 0.01 & 0.049 \pm 0.005 & 0.027 \pm 0.006 \\ \text { Net inflow rate }(1 . / \mathrm{h}) & 0.32 \pm 0.04 & 0.19 \pm 0.02 & 0.1 \mathrm{I} \pm 0.03 \\ \text { Outflow rate }(\mathrm{l} . / \mathrm{h}) & 0.30 \pm 0.03 & 0.19 \pm 0.02 & -\end{array}$

* The average initial rumen volume was $3.7 \pm 0.41$; the average increase for the period $2 \mathrm{r}-30 \mathrm{~h}$ after feeding was $0.08 \pm 0.141$.

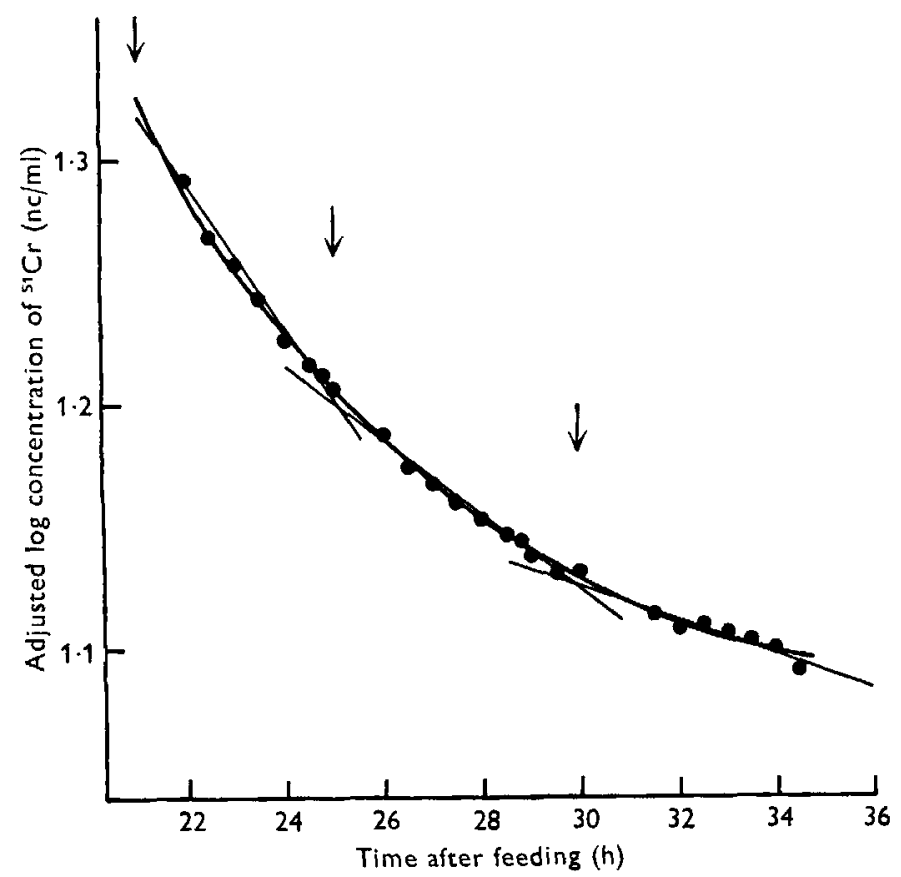

Fig. 5. Effects of starvation on disappearance of marker from the rumen of sheep 2508 . Three doses of marker were given at times indicated by the arrows. In plotting the points, the origins were adjusted to give one continuous curve. Straight lines were drawn in the usual way to fit the points for each dose of marker.

after feeding, and the post-drinking dilution rates and net inflow rates were compared with those found in a similar number of sheep treated in precisely the same way except that no water was offered. In sheep drinking either immediately or a long time $(20 \mathrm{~h})$ after feeding, the dilution rates and net inflow rates were significantly less than in the controls, indeed three out of seven sheep drinking immediately after eating showed negative dilution rates, a phenomenon never found in the controls. The net inflow rate in sheep drinking during the resting period had returned approximately to the values found in the controls at about $5 \mathrm{~h}$ after drinking. Sheep drinking $4.5 \mathrm{~h}$ after feeding did not differ significantly from the controls. 
These results suggest that any effect of drinking on either the rate of salivation or on absorption across the rumen wall was relatively short-lived. On the other hand, in six experiments when the rumen osmotic pressure was reduced some 20-50 m-osmoles/ $\mathrm{kg}$ below the normal resting level by the imbibed water, it was still 10-30 m-osmoles/ $\mathrm{kg}$ below that level, though rising slowly, $5 \mathrm{~h}$ after drinking.

\section{Starving period}

The interval when rumen volume and flow rate may be considered constant is very limited. At least as early as $24 \mathrm{~h}$ after the last feed (Figs. I, 5), the dilution rate may be seen to decrease. When repeated doses of marker were given, it was also found (Table 9) that the net inflow rate and the outflow rate declined; the rumen volume appeared to be increasing slightly, but the change was not statistically significant $(P>0.2)$.

In calculating the figures in Table 9, straight lines were fitted to the points for log marker concentration in the usual way so that three straight-line graphs were obtained for the three additions of marker. However, when the origins of the graphs were adjusted so that all the points were continuous it was seen (Fig. 5) that the linearity of the individual graphs was apparent only, and the line of best fit for all the points was curvilinear.

\section{DISCUSSION}

In the resting state there is approximately as much water in the rumen as there is in the entire circulating blood, yet it is not at all clear how the sheep manages to maintain such a sizeable pool of body fluid in the foregut. The amount of water in the rumen is affected by salivary secretion, trans-epithelial diffusion, ingestion and the passage of contents down the gut. But the overall degree of control exerted by the animal in the integrated functioning of these basic processes has not, by its very complexity, been studied to any great extent. A feasible way of investigating the problem is illustrated by the present work wherein the extensive use of the soluble marker technique has defined, in some detail, the changing picture of fluid movements in the rumen throughout the day.

In a recent report Ternouth (1967) studied water movements in the rumen throughout a feeding cycle and came to conclusions at variance to those reported here. $\mathrm{He}$ concluded that there was a considerable influx of water into the rumen across the rumen wall even when the contents were hypotonic, and that outflow rates occasionally reached values as high as $50 \%$ of the rumen volume per hour. It is difficult to accept these results on physiological grounds, and in view of the many technical inadequacies of the work (Warner \& Stacy, 1968) the validity of the conclusions is open to question. For this reason, no further discussion of the work of Ternouth (1967) is made here.

The general form of the $24 \mathrm{~h}$ marker disappearance curve for sheep fed once daily (Fig. I) has previously been reported from these laboratories (Stacy \& Warner, 1966; Warner, 1966), but it does not seem to have been reported elsewhere. 


\section{Variability of fluid movements in the gut}

It has been a striking feature of the present work that fluid exchanges in the rumen are quite variable. Despite the constancy of experimental conditions (e.g. ambient temperature, dietary regime, rate of eating, etc.) the results varied unpredictably, both within and between animals. Hydén (1961 $a$ ) found similar fluctuations in rumen volume and both he and Tulloh et al. (1965) found considerable variation in net inflow rate. It seems likely that the main cause of the variability is the irregularity in the rate of secretion of saliva (Fig. 2). The other component of the net inflow rate, the rate of absorption of water across the rumen wall, was usually small compared with the salivary inflow rate, except, at times, after drinking (Tables 3 and 8), so that the net inflow rate could be expected to reflect the fluctuations in salivary inflow rate. As a further complication it is likely that fluctuations also occur in the outflow of contents from the reticulum to the omasum and from the omasum to the abomasum (Briggs, 196r; Bost, Verine \& Matrat, 1965). Bruce, Goodall, Kay, Phillipson \& Vowles (I966) found much fluctuation in the rates of flow of digesta through the duodenum and the ileum, and all evidence would suggest that fluid movements throughout the alimentary tract are controlled in an irregular fashion. The flow rate through different parts of the tract fluctuates from time to time and the volume of water that accumulates in the various compartments, particularly the reticulo-rumen, shows considerable variation. These random fluctuations in flow rates and volumes do not prevent animals from having characteristically high or low values, nor do they prevent animals from exhibiting characteristic responses to feeding or drinking.

\section{Rumen volume}

Purser \& Moir (1966), by imprecise means, found that fast eaters tended to have larger resting rumen volumes. While our results also showed this tendency, it did not nearly reach statistical significance. The resting rumen volume was not constant, but changed at rates up to $0.151 . / \mathrm{h}$ in individual experiments summarized in Table 9. During feeding, there appeared to be considerable activity within the rumen. Despite a large influx of water as saliva, the contents were very well mixed, since there was a reasonably smooth decline in marker concentration with time, as illustrated in Fig. 3 . In slow eaters, the rumen volume showed little change during feeding, but in fast eaters it expanded considerably and the rate of outflow failed to match the considerable rate of inflow. It should of course be noted that the slow eaters were not permitted to consume all their ration on the day of an actual experiment. However, it seems likely that, as the rate of eating declined towards the end of the normal 2-4 $\mathrm{h}$ feeding period, the rate of secretion of saliva would also have declined, so that little further change in rumen volume would have been expected. Under the present conditions when all or most of the day's intake of water was consumed in one drink the immediate consequence of drinking was an expansion of the rumen volume. Following eating or drinking, the rumen volume tended to return to a resting value over the next few hours, but the new level was often quite different from the initial one. 


\section{Salivary flow rates}

The major determinant of the net inflow rate is the rate of secretion of saliva. Kay (I966) has recently reviewed the extensive work that has been done to elucidate the factors affecting the function of the salivary glands. In the present context it suffices to consider only a few of these factors. Feeding greatly stimulates salivary flow, but the amount of saliva secreted per $g$ food consumed tends to decline as feeding progresses (Bailey, 196r). In the current work, the initial very high dilution rate often declined as feeding progressed; however, the rate of consumption of feed also decreased (Fig. 3) and it was not possible to demonstrate a decreased ratio of inflow to food consumption. After feeding (Bailey, 1961, r966) or drinking (Wilson, 1963) the rate of salivary secretion has been found to decrease temporarily; it then rises again over a period of a few hours. This phenomenon was amply demonstrated after feeding (Table 4), but the situation after drinking was not so clear-cut. Although in some experiments (Fig. 4) the dilution rate returned to normal $4 \mathrm{~h}$ after entry of water to the rumen, in others (Table 8) it remained depressed for periods up to Io $h$. It seemed that the addition of water to the rumen, by injection or drinking, did not always have a predictable effect on the function of the salivary glands, but this point was not pursued further in the present studies.

Rumination is also known to stimulate salivary secretion (Bailey, 1961); indeed, rumination may be a greater stimulus to parotid secretion than eating (Brüggemann, Walser-Kärst \& Giesecke, 1965). Rough calculations showed that to detect the effect of rumination in a marker experiment with certainty it would be necessary to have a quiescent period (no rumination) of at least $2 \mathrm{~h}$ followed by uninterrupted rumination for at least $0.5 \mathrm{~h}$, followed by another quiescent period of $2 \mathrm{~h}$ or more. The sheep in our experiments did not conform to this pattern of behaviour and no direct effect of rumination has been noticed. Rumination was often observed for short periods, and although sampling often interrupted it there did not appear to be notably more cudchewing on days when there was no experiment. There was some evidence of increased rumination late at night and early in the morning, which may perhaps have contributed to the increased net inflow rate following the post-prandial decline.

\section{Trans-epithelial movements of water}

The other determinant of the net inflow rate is the rate of movement of water across the rumen wall, an important physiological process about which very little is known.

When food is eaten, the rumen contents become hypertonic (Warner \& Stacy, $1_{9} 65$ ), and osmolalities up to nearly $500 \mathrm{~m}$-osmoles/kg have been found in the current experiments. Despite the osmotic gradient between the blood and the rumen contents, no evidence has been found for any substantial movement of water into the rumen across the rumen wall. This was certainly true of the experiments with the slow eaters since the rate of saliva secretion, measured in animals with oesophageal fistulas, equalled the net inflow rate during eating. There is no reason to suspect that the situation would have been different with the fast eaters. Their average net inflow rate was $1 \cdot 201$. in the hour taken to consume $700 \mathrm{~g}$ feed (Table 2 ); a secretory rate of this order would 
seem to be well within the capacity of the ovine salivary glands (unpublished observations). Likewise, in acute experiments with washed-out, isolated rumen preparations in anaesthetized sheep influxes of only about $0.101 . / \mathrm{h}$ were found into a salt solution of about $340 \mathrm{~m}$-osmoles $/ \mathrm{kg}$ (Dobson \& Phillipson, $195^{8}$ ) or of $0.03 \mathrm{l} / \mathrm{h}$ into a solution of about $400 \mathrm{~m}$-osmoles $/ \mathrm{kg}$ (Parthasarathy \& Phillipson, 1953). When the osmotic pressure was raised to about $600 \mathrm{~m}$-osmoles $/ \mathrm{kg}$ the rate of influx of water was still only about 0.26 1./h (Parthasarathy \& Phillipson, 1953), which is less than the overall average salivary influx rate found in the present work. On the other hand, the high rate of $0.681 . / \mathrm{h}$ can be calculated from work with rumen pouches by Tsuda (1964), assuming a pouch:rumen volume ratio of $\mathrm{I}: \mathrm{I} 00$ (Tsuda, 1957), but such a value was only obtained when the solution in the pouch ( $9 \%$ sodium chloride) was of a tonicity well beyond any possible physiological range. It would seem that during normal feeding little water moves into the rumen across the rumen wall.

By contrast, water is absorbed into the blood from the isotonic or hypotonic rumen, but again the rates are low. Thus, Hydén $(196 \mathrm{I} b)$ found an average rate of absorption of $0.15 \mathrm{l} / \mathrm{h}$ in unspecified experimental conditions, Parthasarathy \& Phillipson (I953) in acute experiments found absorption rates of $0.131 . / \mathrm{h}$ from isotonic solutions and a similar value may be calculated from the rumen pouch values of Tsuda (1964). All these values are rather higher than the average of 0.051 ./ h found in the present work for the resting absorption rate. These rates are somewhat increased when the rumen contents become hypotonic. Parthasarathy \& Phillipson (1953) found that about 0.231 . $/ \mathrm{h}$ was absorbed from solutions of $150-200 \mathrm{~m}$-osmoles $/ \mathrm{kg}$, while a rate of $0.131 . / \mathrm{h}$ from distilled water may be calculated from the results of Tsuda (1964). These values may be compared with the $0.10-0.241 . / \mathrm{h}$ absorbed from the rumen after injection of water in the present work (Table 8 ), when the rumen osmotic pressure was $150-200 \mathrm{~m}$-osmoles $/ \mathrm{kg}$.

In several experiments when sheep drank normally (e.g. Tables 5 and 7 ) the results suggested that a small but variable amount of water either bypassed the rumen down the reticular groove into the omasum or was absorbed soon after ingestion. No distinctions can be drawn between these two possibilities for the experiments of Table 7 , but it should be noted that the osmotic gradient would favour absorption in these experiments compared with those typified in Table 5. Indeed, there are several reasons why it is unlikely that absorption played a prominent part in the latter experiments. To account for the results it would be necessary to postulate a rate of absorption (up to $0.81 . / \mathrm{h}$ ) higher than any values reported previously and furthermore that absorption would have occurred in response to a small or negligible osmotic gradient. Now, the net inflow rates were much the same before and after drinking (Table 5) so the absorption rates must also have been similar since there is no reason to suspect that the salivary secretion rate increased greatly after drinking. Therefore, if the rate of absorption were high during the drinking period it must have fallen abruptly in the postdrinking period and these relatively large fluctuations in absorption would have taken place in the presence of relatively minor variations in the tonicity of the rumen contents. On the other hand if it is postulated that some of the ingested water did not enter the rumen, no further special assumptions need be made. Moreover, the postulate is quite 
in accord with the work of Watson (1944) who, in a comprehensive study of the course of liquids through the foregut of sheep, found that on many occasions a small but variable proportion of the imbibed water passed directly to the abomasum down the reticular groove.

To summarize, all the evidence in the above discussion suggests that the rate of absorption of water from the rumen is at all times low, rarely reaching $0.31 . / \mathrm{h}$ even for short periods. This is consistent with our previous finding that it takes a long time for the osmotic pressure of the rumen contents to be restored to pre-drinking values (Warner \& Stacy, 1965). An opposite opinion on this matter has been expressed in recent reviews; thus, Kay (1966) says that 'osmotically-free water... is absorbed quite rapidly'. This statement was largely based on the claim that Parthasarathy \& Phillipson (1953) had established that rumen fluid seldom becomes hypotonic to plasma. In fact these authors showed that rumen contents were often hypotonic, a finding since abundantly confirmed by Engelhardt ( 1963 ) and by Warner \& Stacy (1965). In support of his statement Kay (1966) also drew attention to the work of Wilson \& Tribe (1963). However, these workers did not make any measurements of absorption, they merely concluded that some of their findings on the secretion rate of parotid saliva were compatible with the presumption that 'water is rapidly absorbed from the rumen and therefore has little effect on the volume of the rumen contents'. In another recent review Hungate (1966) implied that imbibed water is quickly absorbed since he stated that 'ingested water is absorbed from the rumen rather than...flowing into the omasum'. As evidence Hungate referred to the work of Trautmann (1933). But the subject of water absorption in the rumen is scarcely mentioned in this reference, and Trautmann simply showed that water was able to move across the rumen wall into the blood-a fact no one would now question.

Now while the above reviews give the wrong impression about the rate of water absorption it may still be true that the amount of water absorbed from the rumen over the full day is approximately equal to the daily water intake which the animal usually drinks in a matter of minutes. Most of the experiments described in the present paper deal with more or less normal situations in which relatively small volumes $(1 \cdot 5-2 \cdot 51$.) of ingested water enter the rumen. The rate of absorption of water was found to average $0.051 . / \mathrm{h}$ in the resting period and to increase to $0 . \mathrm{I}-0.31 . / \mathrm{h}$ for a few hours after drinking, and to decrease after feeding. Thus the total amount of water absorbed could be similar to the amount imbibed. Under other conditions, when much larger quantities of water enter the rumen, the absorption rate might be expected to increase, and indirect evidence of this has been noted in some unpublished experiments from this laboratory.

\section{Outflow from the rumen}

As the result of eating or drinking, the rumen volume is usually enlarged, often by more than I 1 . Since movements of water across the rumen wall are very slow, the main mechanism for eliminating the surplus fluid is an increase in the rate of outflow, and it was found that this rate reached a maximum very rapidly. In several series of experiments, the maximum rate averaged approximately $0.71 . / \mathrm{h}$. For example, the 
outflow rate during feeding was 0.71 ./h for fast eaters (Table 2) and also for slow eaters (Table 3); during the first hour after drinking it was $0.61 . / \mathrm{h}$ for resting sheep (Table 7) and probably of the same order for sheep given water shortly after feeding (as in Table 5). These figures have been attained under conditions when water intake varied greatly, and the results suggest that there is a physiological limit to the rate of outflow from the rumen.

\section{Conclusions}

In the light of what has been discussed, it is possible to interpret in some detail the typical marker concentration curves shown in Fig. 1. The resting rumen volumes for sheep 2606 and 2523 were calculated as $4^{\circ} \mathrm{O}$ and 5.51 ., and the overall $24 \mathrm{~h}$ dilution rates as 0.063 and $0.08 \mathrm{I} \mathrm{h}^{-1}$ respectively. Using these values, the average net inflow rates would be 0.25 and $0.451 . /$ h, i.e. $6 . \mathrm{I}$ and 10.7 1 ./day. These values are probably underestimates by $5-10 \%$ since the true average rumen volume probably exceeded the initial value by this amount, based on the extent and duration of the changes in rumen volume that accompanied eating and drinking. Hence, the daily net inflow was probably about 6.5 and II.4 l. respectively; the total daily outflow would have been similar. If the overall average rate of absorption of water from the rumen was $0.051 . / \mathrm{h}$, this would amount to $\mathrm{x} \cdot 2 \mathrm{l}$./day (close to the daily intake, $\mathrm{x} \cdot 5 \mathrm{l}$.), so that the daily amounts of saliva secreted would have been $6 \cdot 2$ and $I \mathrm{I} \cdot \mathrm{I} 1$. respectively. These values are within the normal range for daily saliva production (Denton, 1965; Kay, I966). There may have been a passage of about $0^{\circ} \mathrm{I}$ l. of water down the reticular groove in sheep 2523.

All these findings are, of course, applicable only to the diets and dietary regimes used in this work. One can only speculate on the effects of different diets given in different amounts in different routines. While some evidence exists on the influence of some of these factors on salivary secretion (reviewed by Kay, I966) and on rumen volume (see, for example, Balch \& Line, 1957; Emery, Smith \& Lewis, I958; Johns, Ulyatt \& Glenday, I963; Lawlor, Giesecke \& Walser-Kärst, 1966), these data are plainly insufficient to compute rumen water balances, though they do indicate that considerable differences are to be expected.

The movement of water from the blood to the rumen via saliva and then back from the gut to the blood has been likened to a second circulation (Denton, 1965). The function of the salivary glands in regulating the daily entry of water into the rumen is well recognized (Denton, 1965; Kay, 1966), but there is very little information to indicate how the subsequent movement and absorption of water in the gut is controlled. By providing a clearer description of the fate of water in the rumen the present results help to clarify one aspect of the 'second circulation'.

We wish to give grateful thanks to $\mathrm{Mr} \mathrm{H}$. Weiler for allowing us to make use of his statistical methods in advance of publication. Thanks are also due to Miss $G$. Wheeler and Messrs N. R. Bradbury, A. A. Fawcett and B. W. Wilson for technical assistance, and to Mrs J. Williams for computation. 


\section{REFERENCES}

Bailey, C. B. (1961). Br. F. Nutr. 15, 443 .

Bailey, C. B. (1966). Anim. Prod. 8, 325.

Balch, C. C. \& Line, C. (1957). F. Dairy Res. 24, I1.

Bost, J., Vérine, H. \& Matrat, B. (1965). C. r. Séanc. Soc. biol. 159, 2410.

Briggs, P. K. (196r). PhD Thesis, University of Aberdeen.

Brook, A. H., Radford, H. M. \& Stacy, B. D. (I968). F. Physiol., Lond. (In the Press.)

Bruce, J., Goodall, E. D., Kay, R. N. B., Phillipson, A. T. \& Vowles, L. E. (I966). Proc. R. Soc. B $166,46$.

Brüggemann, J., Walser-Kärst, K. \& Giesecke, D. (1965). Z. Tierphysiol. Tierernähr. Futtermittelk. 20, 261.

Denton, D. A. (1965). Physiol. Rez. 45, 245.

Dixon, W. J. \& Massey, F. J. (1957). Introduction to Statistical Analysis. New York: McGraw-Hill Book Co., Inc.

Dobson, A. \& Phillipson, A. T. (1958). F. Physiol., I.ond. r40, 94.

Emery, R. S., Smith, C. K. \& Lewis, T. R. (1958). F. Dairy Sci. 4r, 647.

Engelhardt, W.v. ( (1963). Pfligers Arch. ges. Physiol. 278, 152.

Hogan, J. P. (1964). Aust. F. agric. Res. 15, 384 .

Hungate, R. E. (1966). The Rumen and its Microbes, p. 218. New York: Academic Press Inc.

Hutton, J. B., Hughes, J. W., Newth, R. P. \& Watanabe, K. (1964). Proc. N.Z. Soc. Anim. Prod. $24,29$.

Hydén, S. (1961 a). K. LantbrHögsk. Annlr 27, 5 I.

Hydén, S. (1961 b). K. LantbrHögsk. Annlr 27, 273.

Johns, A. T., Ulyatt, M. J. \& Glenday, A. C. (1963). F. agric. Sci., Camb. 6r, 201.

Kay, R. N. B. (1966). Wld Rev. Nutr. Diet. 6, 292.

Lawlor, M. J., Giesecke, D. \& Walser-Kärst, K. (1966). Br. F. Nutr. 20, 373.

McManus, W. R., Arnold, G. W. \& Hamilton, F. J. (I962). Aust. vet. F. 38, 275.

Murray, M. G., Reid, R. S. \& Sutherland, T. M. (I 962). F. Physiol., Lond. 164, 26 P.

Parthasarathy, D. \& Phillipson, A. T. (I953). F. Physiol., Lond. 121, 452.

Purser, D. B. \& Moir, R. J. (1966). 7. Anim. Sci. 25, 509.

Reid, C. S. W. (1965). Proc. N.Z. Soc. Anim. Prod. 25, 65.

Stacy, B. D. \& Warner, A. C. I. (ז966). Q. Fl exp. Physiol. 51, 79.

Ternouth, J. H. (1967). Res. vet. Sci. 8, 283 .

Trautmann, A. (1933). Arch. Tierernähr. Tierz. 9, 178.

Tsuda, T. (1957). Tohoku $¥$. agric. Res. 7, 231 .

Tsuda, T. (1964). Tohoku F. agric. Res. 15, 83 .

Tulloh, N. M., Hughes, J. W. \& Newth, R. P. (I 965). N.Z. Fl agric. Res. 8, 636.

Ulyatt, M. J. (1964). N.Z. Yl agric. Res. 7, 713.

Warner, A. C. I. (1966). F. gen. Microbiol. 45, 2 I3.

Warner, A. C. I. \& Stacy, B. D. (1965). Q. भl exp. Physiol. 5o, г69.

Warner, A. C. I. \& Stacy, B. D. (I968). Br. F. Nutr. 22, 369 .

Watson, R. H. (1944). Bull. Coun. scient. ind. Res., Melb. no. 180, p. I.

Wilson, A. D. (1963). Aust. F. agric. Res. 14, 680.

Wilson, A. D. \& Tribe, D. E. (1963). Aust. F. agric. Res. 14, 670 